DOI: $10.1590 / 1809-6891 v 15 i 328351$

\title{
CARACTERIZAÇÃO DE Aeromonas spp ISOLADAS DE AMOSTRAS DE OSTRAS E ÁGUA POR MÉTODO MICROBIOLÓGICO E MOLECULAR
}

\author{
Ana Carolina Miranda de Melo Silva ${ }^{1}$, Daniele Lopes do NASCIMENTO ${ }^{2}$ RosÂngela ZaCARias \\ MACHADO $^{3}$, FRANCISCA NEIDE COSTA $^{4}$
}

\author{
${ }^{1}$ Pós Graduanda da Universidade Estadual do Maranhão, São Luiz, MA, Brasil. \\ ${ }^{2}$ Médica Veterinária, Universidade Estadual do Maranhão, São Luiz, MA, Brasil. \\ ${ }^{3}$ Professora Doutora da Universidade Estadual Paulista, Jaboticabal, SP, Brasil. \\ ${ }^{4}$ Professora Doutora da Universidade Estadual do Maranhão, São Luiz, MA, Brasil - \\ francisca.cca.uema@gmail.com
}

Objetivou-se isolar e identificar bactérias do gênero
Aeromonas de amostras de ostras e de água, pelos
métodos microbiológico e molecular. A identificação do
gênero Aeromonas foi realizada pelo método
convencional e pela técnica da PCR e a caracterização das
espécies foi realizada pela chave de identificação Aerokey
II e pela técnica de RFLP-PCR do 16S rDNA. Foram
identificadas 59 (98,3\%) amostras de ostras e 15 (75\%)
amostras de água contaminadas por bactérias do gênero
Aeromonas. Dos 74 isolados de Aeromonas spp. obtidos
pela análise microbiológica, $53(71,62 \%)$, $38(65,51 \%)$ de
amostras de ostras e 15 (100\%) de amostras de água,
confirmaram a caracterização do gênero pela técnica
molecular. Quanto a identificação bioquímica das espécies
$59,3 \%$ (n=35) e $40,6 \%$ (n=24) dos isolados de Aeromonas

PALAVRAS-CHAVE: água, Aeromonas, ostras, PCR. sp. obtidos das amostras de ostras foram classificados como A. hydrophila e A. caviae, respectivamente; e para os isolados obtidos das amostras de água, 60\% $(\mathrm{n}=9)$ foram classificados como $A$. hydrophila e $40 \% \quad(\mathrm{n}=6)$ como $A$. caviae; entretanto, somente a $A$. hydrophila foi confirmada pelo sequenciamento genético. Quanto a classificação através da RFLP-PCR 16S rDNA, foram obtidos padrões de bandas inespecíficos, impossibilitando a identificação das espécies por esta técnica. O grande número de amostras de ostras contaminadas com Aeromonas spp. e a identificação da $A$. hydrophila demonstram que este molusco pode oferecer risco à saúde dos consumidores, principalmente por ser consumido in natura e se tratar de um micro-organismo potencialmente patogênico para o ser humano.

\section{CHARACTERIZATION OF Aeromonas spp ISOLATED FROM WATER AND OF OYSTERS SAMPLES BY MICROBIOLOGICAL AND MOLECULAR METHODS}

\section{ABSTRACT}

This study aimed to isolate and identify Aeromonas bacteria from samples of oysters and water, by microbiological and molecular methods. Identification of Aeromonas was performed by the conventional method and by PCR and species characterization was performed by identification key Aerokey II and by RFLP-PCR of 16S rDNA. 59 (98.3\%) samples of oysters and $15(75 \%)$ samples of water contaminated by Aeromonas bacteria were identified. Of the 74 isolates of Aeromonas spp. obtained by microbiological analysis, $53(71.62 \%), 38$ (65.51\%) oyster samples and $15(100 \%)$ of water samples confirmed the characterization of the genus by molecular technique. As to biochemical species identification, 59.3\% $(\mathrm{n}=35)$ and $40.6 \%(\mathrm{n}=24)$ of isolates from Aeromonas sp. obtained from oyster samples were rated as $A$. hydrophila and A. caviae, respectively; and from isolates obtained from water samples, $60 \%(\mathrm{n}=9)$ were classified as $A$. hydrophila and $40 \%(\mathrm{n}=6)$ as $A$. caviae; however, 
only the $A$. hydrophila was confirmed by genetic sequencing. Regarding the classification by RFLP-PCR 16S rDNA, patterns of nonspecific bands were obtained, making it impossible to identify the species by this technique. The large number of oyester samples

KEYWORDS: Aeromonas, oysters, PCR, water.

\section{INTRODUÇÃO}

As intoxicações alimentares causadas por bactérias patogênicas de origem marinha são normalmente decorrentes do consumo de ostras cruas, de produtos pesqueiros crus, defumados, fermentados e salgados e de crustáceos crus ou insuficientemente $\operatorname{cozidos}^{1}$. As ostras são normalmente consumidas in natura e, neste caso, os moluscos são ingeridos como um todo, levando à transmissão de micro-organismos potencialmente patogênicos para o consumidor, fato que aumenta o risco de doenças transmitidas por alimentos, especialmente quando esses moluscos são provenientes de áreas contaminadas ou tratados em condições higiênico-sanitárias precárias ${ }^{2}$.

Surtos de doenças bacterianas de origem alimentar são reportados em todo o planeta, alguns causados por agentes denominados clássicos, como Staphylococcus aureus, Clostridium perfringens e Salmonella spp., mas a grande maioria é ocasionada por bactérias emergentes, entre as quais as do gênero Aeromonas ${ }^{3}$. A Organização Mundial da Saúde (OMS), em 2002, e a Agência de Proteção Ambiental (EPA) dos Estados Unidos, em 2006, descreveram o gênero Aeromonas como patógeno emergente. Esse gênero tem recebido atenção especial nos últimos anos, por estar relacionado com várias doenças em humanos e animais e, principalmente, pela sua potencialidade de patógeno oportunista em indivíduos imunodeprimidos ${ }^{4}$. Bactérias do gênero Aeromonas são amplamente difundidas no meio ambiente, estando presentes nos meios aquáticos, nos animais e nos alimentos. Seu isolamento em produtos de origem animal foi relatado por diversos pesquisadores em diferentes partes do mundo, sendo que a grande maioria está associada ao pescado ${ }^{5}$, dentre os quais se destacam as ostras. Além disso, neste papel de "patógeno secundário", as Aeromonas têm sido implicadas como potenciais causadoras de gastrenterites e infecções extra-intestinais, incluindo as infecções de feridas, pneumonia, síndrome urêmica hemolítica, peritonites, sépsis biliares e septicemias ${ }^{6}$.

Dessa forma, a identificação rápida dos contaminated with Aeromonas spp. and identification of A. hydrophila, demonstrate that this mollusk might present a risk to consumer health, mainly because it is consumed raw and is to a potentially pathogenic micro-organism to humans.

agentes causadores das doenças de origem alimentar é um passo importante para a tomada de decisão em casos de surtos. Para o isolamento das bactérias do gênero Aeromonas, os métodos microbiológicos são largamente empregados, porém, devido à necessidade de se diminuir o tempo de isolamento e aumentar a precisão dos testes diagnósticos aliado a dificuldade de padronização dos resultados bioquímicos ${ }^{7}$, tem-se utilizado ferramentas moleculares para diagnóstico, destacando-se a reação em cadeia pela polimerase $-\mathrm{PCR}^{8}$ e as técnicas de Polimorfismo de Fragmento de Restrição Lento (RFLPRestriction Fragment Length Polymorphism) do $16 \mathrm{~S} \mathrm{rDNA}^{9}$.

Assim, devido à importância das bactérias do gênero Aeromonas como micro-organismos patogênicos para o ser humano, principalmente no que diz respeito à sua implicação na saúde pública, e devido à escassa literatura científica sobre a presença deste patógeno em ostras, objetivou-se com este trabalho isolar e caracterizar as bactérias do gênero Aeromonas em amostras de água e ostras pelos métodos bioquímicos e moleculares.

\section{MATERIAL E MÉTODOS}

Utilizaram-se, neste estudo, 60 amostras de ostras e 20 amostras de água, obtidas de locais de cultivo e pesca nos municípios de Raposa e Humberto de Campos no Estado do MaranhãoBrasil. A amostragem das ostras foi realizada conforme metodologia utilizada por Pereira et al. ${ }^{2}$, na qual cada amostra de ostra foi constituída de 12 unidades e as técnicas de coleta, armazenamento e transporte foram realizadas obedecendo-se ao Manual de Métodos de Análise Microbiológica de Alimentos ${ }^{10}$. O material oriundo das ostras foi mantido em Caldo Tripticase Soja (TSB), adicionado de ampicilina, e as amostras de água foram filtradas em membranas de éster de celulose, as quais foram picadas e os fragmentos colocados em Erlenmeyer, contendo $100 \mathrm{~mL}$ de TSB, e incubadas em estufa à temperatura de 28 ${ }^{\circ} \mathrm{C}$ por 24 horas ${ }^{11}$. Alíquotas dos caldos de enriquecimento seletivo foram semeadas em ágar 
dextrina-ampicilina e ágar vermelho de fenolamido-ampicilina e incubadas à temperatura de 28 ${ }^{\circ} \mathrm{C}$ por 24 horas. As colônias sugestivas, em número de até cinco por amostra, foram semeadas em Ágar Tripticase Soja (TSA) inclinado e incubadas em estufa à temperatura de $28{ }^{\circ} \mathrm{C}$, por 24 horas.

Para a identificação do gênero Aeromonas, realizou-se a coloração de Gram e as culturas que apresentavam forma de bastonetes retos e curtos e gram-negativas foram repicadas em Ágar TrípliceAçúcar-Ferro (TSI) e incubadas à temperatura de $28{ }^{\circ} \mathrm{C}$ por 24 horas. As culturas que apresentaram reação ácida foram repicadas em TSA e submetidas às provas da oxidase e da catalase, considerando-se como Aeromonas spp. os cultivos positivos nestas provas. A caracterização dos isolados de Aeromonas spp foi realizada utilizando-se a chave de classificação Aerokey II $^{12}$.

As bactérias com perfil fenotípico de Aeromonas spp foram submetidas à reação em cadeia da polimerase (PCR), seguida de restrição enzimática para caracterização das espécies bacterianas. A PCR foi realizada utilizando-se um par de iniciadores, com base nas sequências do 16S rDNA, gênero-específico para o gênero Aeromonas (Aero16-Fw 5'TGACGTTACTCGCAGAAGA-3' e Aero 16-rev 5'-GCTTGCAGCCCTCTGT ACG-3'), proposto por Uehara ${ }^{13}$, em que sua amplificação resulta em um fragmento de 787 bp. Foi usada como controle positivo uma cepa de referência de Aeromonas hydrophila ATCC 7966, gentilmente cedida pela Fundação Oswaldo Cruz/Rio de Janeiro. As reações de amplificação foram realizadas em volumes de $25 \mu \mathrm{L}$, contendo $3 \mu \mathrm{L}$ de DNA $(50 \mathrm{ug} / \mu \mathrm{L}) ; 5 \mu \mathrm{L}$ de tampão $5 \mathrm{x} ; 1,5 \mathrm{mM}$ de cloreto de magnésio; $200 \mu \mathrm{M}$ DNTP; 0,2 $\mu \mathrm{M}$ de cada iniciador, 1,25U de Taq polimerase (Invitrogen) e água Milli Q q.s.p25 $\mathrm{L}$ e para amplificação foi utilizado um ciclo inicial a $95{ }^{\circ} \mathrm{C}$ por cinco minutos; 30 ciclos compreendendo desnaturação a $95{ }^{\circ} \mathrm{C}$ por um minuto, anelamento a $66{ }^{\circ} \mathrm{C}$ por um minuto e extensão a $72{ }^{\circ} \mathrm{C}$ por um minuto; e um único ciclo de extensão final a $72{ }^{\circ} \mathrm{C}$ por cinco minutos e manutenção a $4{ }^{\circ} \mathrm{C}$.

Para a identificação das espécies, foi realizada a técnica de RFLP-PCR, gene $16 \mathrm{~S}$ rDNA, segundo protocolo proposto por Borrell et al. ${ }^{9}$. Para amplificação do gene foram utilizados os primers 16SAer-F 5 'AGAGTTTGATCATGGCTCAG-3' e 16SAer-R
5'- GGTTACCTT GTTACGACTT-3' ' . As reações de amplificação foram realizadas em volumes de $50 \mu \mathrm{L}$, contendo $2 \mu \mathrm{L}$ de DNA; $5 \mu \mathrm{L}$ de tampão 10x; $1,5 \mathrm{mM}$ de cloreto de magnésio; $0,2 \mathrm{mM}$ de DNTP; $1 \mu \mathrm{L}$ de cada iniciador, $2 \mathrm{U}$ de Taq DNA polimerase (Invitrogen) e água Milli Q q.s.p $50 \mu \mathrm{L}$ e para amplificação foi empregado um ciclo inicial a $93{ }^{\circ} \mathrm{C}$ por três minutos; 35 ciclos compreendendo desnaturação a $94{ }^{\circ} \mathrm{C}$ por um minuto, anelamento a $56{ }^{\circ} \mathrm{C}$ por um minuto e extensão a temperatura de $72^{\circ} \mathrm{C}$ por dois minuto; e um único ciclo de extensão final a $72{ }^{\circ} \mathrm{C}$ por 10 minutos $\mathrm{e}$ manutenção a $4^{\circ} \mathrm{C}$.

Todas as amostras de DNA de Aeromonas spp. foram submetidas a PCR com os primers gênero-específico e cerca de $250 \mu \mathrm{L}$ do amplicom resultante foram purificados utilizando-se o Kit de Purificação (Purextreme Silica Bead DNA Gel Extraction Kit, Fermentas). Os produtos purificados foram submetidos ao sequenciamento genético, em um sequenciador automático $\mathrm{ABI}$ $3730 \mathrm{XL}$, conforme recomendações sugeridas pelo fabricante do equipamento (Applied Biosystems).

As sequências obtidas foram analisadas e comparadas com as sequências depositadas no GenBank, pelo programa BLASTn. Para um alto nível de qualidade das sequências, admitiram-se índices de confiança para cada nucleotídeo acima de $97 \%$ e níveis de identidade de sequência acima de $93 \%$, em que $\mathrm{E}=0.0$.

Os dados foram analisados pelo teste de Qui-quadrado ou teste de Fisher, com nível estipulado de significância de 5\%.

\section{RESULTADOS E DISCUSSÃO}

Os resultados da caracterização bioquímica dos isolados demonstraram que 98,3\% ( $\mathrm{n}=59)$ e $75 \% \quad(n=15)$ das ostras e das águas, respectivamente, estavam contaminadas por Aeromonas spp. A identificação do gênero Aeromonas pela PCR demonstrou que $38(65,51 \%)$ dos isolados obtidos de amostras de ostras e 15 $(100 \%)$ dos isolados das amostras de água foram confirmadas e caracterizadas como pertencentes ao gênero da bactéria em estudo, ou seja, 71,62\% (n= 53 ) do total dos isolados foram identificados como Aeromonas spp pelo método molecular. Aplicando-se o teste do Qui-quadrado para verificar a interdependência dos resultados frente ao teste diagnóstico efetuado, verificou-se que houve dependência dos testes $\left(x^{2}=11,59\right.$; $\mathrm{P}=0,0007)$, ou seja, os resultados obtidos podem 
variar de acordo com o teste usado.

$\mathrm{Na}$ figura 1 estão apresentados os resultados da caracterização molecular do gênero Aeromonas de apenas 31 isolados obtidos de amostras de ostra e água, onde se observa que os isolados com um fragmento de $787 \mathrm{pb}$, a semelhança do controle positivo (Aeromonas hydrophila ATCC 7966), confirmam ser pertencentes ao gênero Aeromonas.

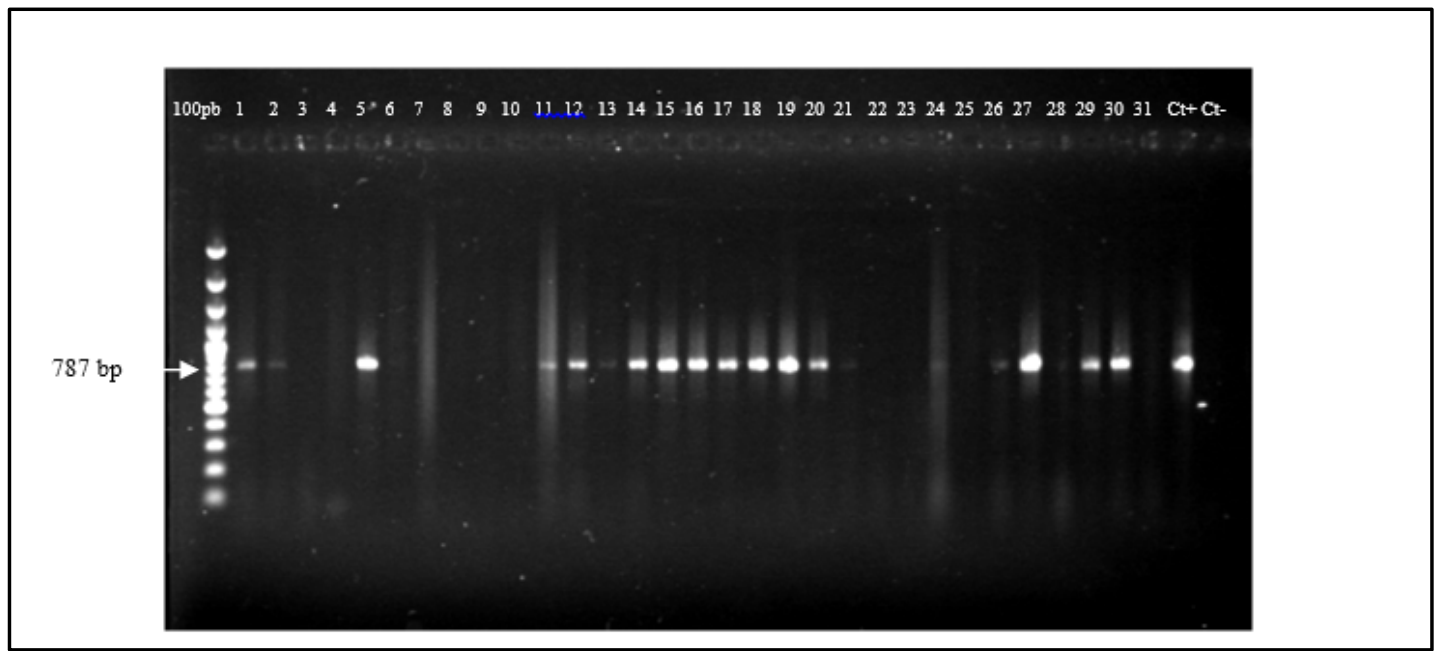

Figura 1. Fragmento de 787 bp amplificado a partir de um par de iniciadores gênero-específico para Aeromonas em gel de agarose a 1,5\%. Linha 1 até 31 - isolados de Aeromonas spp., previamente identificadas por testes bioquímicos. $\mathrm{Ct}+$ : controle positivo (Aeromonas hydrophila ATCC 7966). Ct: controle negativo (água Milli Q).

Os percentuais de contaminação das ostras encontrados nesta pesquisa foram superiores aos encontrados por Evangelista-Barreto et. al. ${ }^{14}$, os quais isolaram amostras de Aeromonas spp. em 50\% das ostras analisadas de um criadouro natural, no estuário do rio Cocó (Fortaleza/Ceará/Brasil). Já Gomes ${ }^{15}$ isolou Aeromonas sp. em $10,7 \%$ das amostras de ostras comercializadas na cidade de São Paulo, enquanto Colakoglu et al. ${ }^{16}$ identificaram $66 \%$ $(n=84)$ amostras de ostras, procedentes de mercados de peixes locais e de cozinhas de hotéis na região de Dardanelos/Turquia, contaminadas por Aeromonas spp.

O grande percentual de amostras de água contaminadas por Aeromonas indicam que os locais são impróprios para a pesca e cultivo de ostra, sendo necessária a realização de algum tipo de tratamento antes da comercialização e consumo desse alimento.

Corroborando com estas afirmações, Galvão et al. $^{17}$ afirmaram que a contaminação de águas costeiras pode ameaçar seu uso potencial para o cultivo de moluscos bivalves, pois, sendo organismos filtradores, têm capacidade de concentrar e acumular altas densidades de micro-organismos. Desta forma, é importante ressaltar que o tratamento das águas utilizadas para o cultivo de ostras e o uso de um processo de depuração aliado ou não a um tratamento térmico são alternativas importantes para diminuição da contaminação microbiana dos moluscos bivalves, pois possibilitam um produto final mais seguro ao consumidor deste alimento. Procedimentos como estes devem ser levados em consideração quando se trata do consumo de ostras.

Com relação à caracterização das espécies, pelo método bioquímico, observou-se que de um total de 59 isolados de Aeromonas spp. obtidos das amostras de ostras, 35 (59,5\%) foram confirmados como Aeromonas hydrophila e os demais, 24 (40,6\%), foram classificados como Aeromonas caviae. Quanto às amostras de água, de um total de 15 isolados de Aeromonas spp. nove (60\%) foram classificados como A. hydrophila e seis (40\%) como A. caviae.

Pelo sequenciamento genético, confirmou-se a presença de Aeromonas sp e a espécie $A$. hydrophila, além da espécie $A$. media, não isolada pelo método convencional. A identificação de espécie diferente, como a A. media, reforça a importância do uso de ferramentas moleculares, como o sequenciamento genético, para a confirmação dos resultados dos testes bioquímicos, principalmente quando estes apresentam resultados inconclusivos.

$\mathrm{O}$ isolamento da espécie $A$. hydrophila, das amostras em estudo revela o grande risco do consumo de ostras provenientes de águas não tratadas e que não passam por processo de depuração, uma vez que esta espécie é reconhecida como patogênica para o ser humano, pois, segundo Pereira et al. ${ }^{18}$, esta espécie esta envolvida em casos 
de diarreia infantil, infecção hospitalar, ou gastrenterites causadas por ingestão de alimentos como ostras, mexilhões, pescados e vegetais. A presença de espécies de $A$. media nas amostras de ostra também pode oferecer risco aos consumidores. Essa espécie geralmente está envolvida em casos de diarréias agudas amenas e em quadros graves de disenteria

Corroborando com os achados desta pesquisa, ressaltam-se os trabalhos realizados por Mendes ${ }^{1}$, identificando a espécie $A$. hydrophila em $77,78 \%$ das amostras de ostras, e por Pereira ${ }^{18}$ que isolou A. hydrophila em $15,50 \%$ das amostras de mexilhões na Baía de Guanabara.

Os resultados obtidos pela identificação molecular do gênero Aeromonas sugerem que podem existir falhas na identificação bioquímica desta bactéria, uma vez que os testes bioquímicos podem gerar resultados duvidosos ${ }^{18,19} \mathrm{e}$ muitas vezes são incapazes de identificar com a devida precisão as espécies de Aeromonas face à homogeneidade fenotípica existente dentro deste gênero ${ }^{18,20}$.

Os padrões de bandas encontrados neste estudo foram diferentes dos descritos por Borrell et al. ${ }^{9}$, não sendo possível, assim, a caracterização das espécies de Aeromonas através do método de RFLPPCR 16S rDNA.

Segundo Kozinska et al. $^{20}$ e CastroEscarpulli et al. ${ }^{22}$, diferenças na caracterização das espécies de bactérias do gênero Aeromonas foram identificadas quando os métodos bioquímicos e moleculares foram comparados por vários pesquisadores. O uso dos testes bioquímicos pode tornar-se difícil, principalmente devido à homogeneidade fenotípica das espécies do gênero Aeromonas $^{21}$. Por outro lado, Graf ${ }^{23}$ relatou que, em algumas condições clínicas, os testes bioquímicos ainda devem ser usados, especialmente naqueles casos em que as técnicas moleculares geram resultados controversos, como no caso desta pesquisa, em que não foi possível a identificação das espécies de Aeromonas pelo método de RFLP-PCR
16S rDNA.

Resultados discrepantes entre estas duas técnicas também foram descritos por Ormen et al. ${ }^{24}$ na identificação das espécies de Aeromonas em isolados clínicos e ambientais. Estes autores citam que os testes bioquímicos usam esquemas de identificação baseados em isolados clínicos e estes não podem ser aplicados por fornecerem incompleta identificação de isolados ambientais, além disso, a grande heterogeneidade genética das amostras ambientais pode influenciar nos resultados. Corroborando com esta afirmação, Huys et al. ${ }^{25}$ demonstraram por métodos moleculares que há uma grande variação genética dos isolados de $A$. hydrophila, sugerindo a existência de uma subespécie. A grande variação genética dentro do gênero Aeromonas foi indicada também por MiñanaGalbis et al. ${ }^{26}$, os quais identificaram a presença de uma nova espécie nos isolados de moluscos bivalves. Utilizando a técnica de RFLP para identificação das espécies de Aeromonas, provenientes de várias fontes, Alperi et $\mathrm{al}^{27}$ verificaram que $8,1 \%$ das amostras apresentaram padrões de bandas diferentes, levando à identificação duvidosa destas amostras. Para esses autores a microheterogeneidade dos nucleotídeos destas espécies deve ser levada em consideração, quando se usam a RFLP ou outras técnicas moleculares.

Conforme mostra a literatura, a formação dos padrões de bandas diferentes encontradas neste estudo (Figura 2) pode ser resultado de um conjunto de causas, podendo estar principalmente relacionada à grande variação genética das bactérias do gênero Aeromonas, principalmente em amostras ambientais.

$\mathrm{O}$ uso de outros métodos moleculares associados à técnica da RFLP poderia aumentar o potencial discriminatório por detectar um número maior de polimorfismos, aumentando, assim, a confiança no resultado. Portanto, a combinação de mais de um método molecular para caracterização genética das Aeromonas sp. deve ser levada em consideração. 


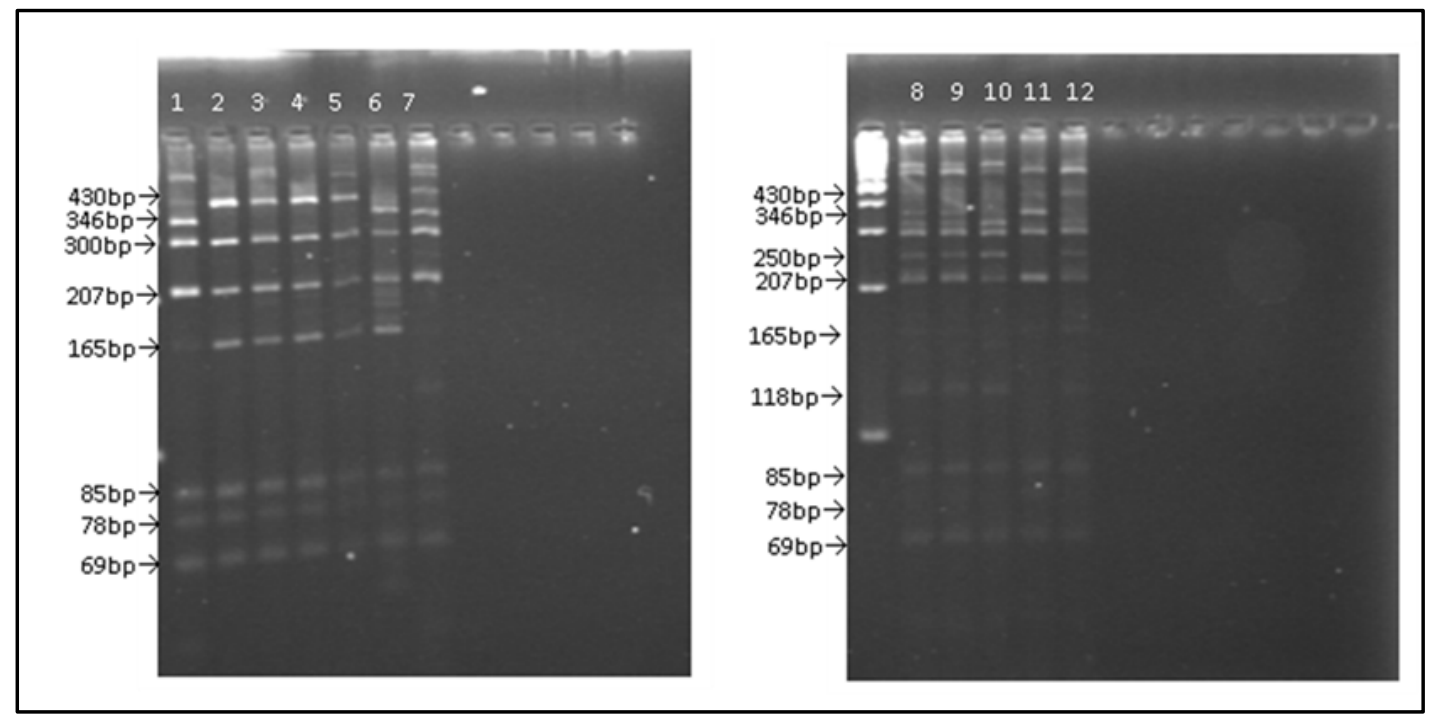

Fig. 2. Isolados de Aeromonas spp. digeridas com as enzimas de restrição Alu I e MboI. De 1 até 10 padrão de banda dos isolados obtidos de amostras de ostra; 11 e 12 - isolados obtidos de amostras de água.

\section{CONCLUSÃO}

A identificação da espécie Aeromonas hydrophila nas amostras de ostras demonstra que este molusco pode oferecer risco à saúde dos consumidores e reforça a necessidade de atenção com a segurança microbiológica deste alimento. Enfatiza-se ainda que para a identificação das bactérias do gênero Aeromonas o uso de ferramentas moleculares, como o sequenciamento genético, torna-se importante, uma vez que resultados duvidosos podem ser obtidos na identificação bioquímica e a impossibilidade de identificação das espécies de Aeromonas pode ocorrer quando do uso da técnica de RFLP.

\section{AGRADECIMENTOS}

À Universidade Estadual Paulista - UNESP (Campus de Jaboticabal), por permitir a realização dos estudos bioquímicos e moleculares desta pesquisa. Ao laboratório de Microbiologia de Alimentos e Água da Universidade Estadual do Maranhão - UEMA, onde foi realizada a primeira etapa da pesquisa. À Fundação de Amparo à Pesquisa e Desenvolvimento Científico do Maranhão - FAPEMA, pela concessão de bolsa de mestrado, e ao Conselho Nacional de Desenvolvimento Científico e Tecnológico (CNPq).

\section{REFERÊNCIAS}

1. Mendes ES, Lopes PP, Magalhães CA, Coelho MIS, Souza JCR, Cruz MCS, et al . Sazonalidade dos micro-organismos em ostras consumidas na grande Recife, PE. Hig. Alim. 2004; 18: 79-87.
2. Pereira MA, Nunes MM, Nuernberg L, Schulz D, Batista CRV. Microbiological quality of oysters (Crassostrea gigas) produced and commercialized in the coastal region of Florianópolis - Brazil. Braz. J. Microbiol. 2006 Fev 26; 37 (2): 159-62.

3. Lucena RF, Delamare APL, Thomazi G, Ferrarini S, Zacaria, J e Echeverrigaray S. Aeromonas detection and characterization using genus-specific PCR and single-strand conformation polymorphism (SSCP).World Journal of Microbiology and Biotechnology. 2012; 28 (8): 3007-3013.

4. Martins AGLA, Nascimento AR, Vieira RHSF, Serra JL, Rocha MMRM. Quantificação e identificação de Aeromonas spp. em águas de superfície do estuário do rio Bacanga em São Luís / MA (Brasil). Boletim Ceppa. 2009; 27: 107-18.

5. Costa FN, Rossi Júnior OD. Bactérias do gênero Aeromonas em abatedouro de frangos. Arq. Bra. Méd. Vet. Zoot, 2002; 54 (5): 534-5.

6. Chan, F.K.L., Ching, J.Y.L., Ling, T.K.W., Chung, S.C.S., Sung, J.J.Y. Aeromonas infection in acute suppurative cholangitis: review of 30 cases. J. Infection, 2000; 40 (1): 69-73.

7. Ozbas ZY, Lehner A, Wagner M. Development of a multiplex and semi-nested PCR assay for detection ofYersinia enterocolitica and Aeromonas hydrophila in rawmilk. Food Microbiol. 2000; 17 (2): 197-203.

8. Santos LR, Nascimento VP, Oliveira SD, Flores ML, Pilotto F, Pontes AP, et al. Identificação de Salmonella através da reação em cadeia pela polimerase (PCR). Arq. Fac. Vet. 2001; 29 (2): 8792.

9. Borrell N, Acinas SG, Figueras MJ, Martinez-Murcia AJ. Identification of Aeromonas clinical isolates by restriction fragment length polymorphism of PCRamplified 16S rRNA genes. J. Clin. Microbiol. 1997; 
35 (7): $1671-4$.

10. Silva, N da, Junqueira, V.C.A., Silveira, N.F.A. Manual de Métodos de Análise Microbiológica de Alimentos. $2^{\circ}$ edição. Editora Varela. São Paulo, 2001

11. Costa FN, Rossi Júnior OD. Enterotoxigenicidade e espécies de Aeromonas isoladas em diferentes pontos do fluxograma de abate de frangos. Arq. Inst. Biol. 2007; 74 (1): 5-9.

12. Carnahan AM, Behram S, Joseph SW. Aerokey II: aflexible Key for identifying clinical Aeromonas sp.ecies. J. clin.Microbiol.1991; 29 (12): 2843-9.

13. Uehara FI. Concordância entre o perfil de restrição do fragmento $16 \mathrm{~S}$ rDNA e testes fenotípicos para determinação do posicionamento taxonômico de cepas de Aeromonas [dissertação]. São Paulo (SP): Faculdade de Saúde Pública da Universidade de São Paulo. 2008.

14. Evangelista-Barreto NS, Vieira RHSF, Carvalho FCT, Torres RCO, Sant'anna ES, Rodrigues DP, et al. Aeromonas spp. Isolated from oysters (Crassostrea rhizophoerea) from a natural oyster bed, Ceará, Brazil. Rev. Inst. Med. Trop. 2006; 48 (3): 129-133.

15. Gomes ML. Quantificação de Aeromonas sp em amostras de ostras e relação com coliformes fecais e estreptococos fecais. Produção de enterotoxina e sensibilidade a antibióticos a partir das cepas isoladas [internet] 2002 [acesso em 15 de outubro de 2009]. Disponível http://en.scientificcommons.org/33797824.

16. Colakoglu FA, Sarmasik A, Koseoglu B. Occurrence of Vibrio spp.And Aeromonas spp. In shellfish harvested off Dardanelles cost of Turkey. Food Control. 2006; 17 (8): 648-52.

17. Galvão JA, Furlan EF, Salán EO, Porto P, Oetterer M. Características físico-químicas e microbiológicas (Staphylococcus aureus e Bacillus cereus) da água e dos mexilhões cultivados na região de Ubatuba, SP. Ciênc. agrotec. 2006; 30 (6): 1124-9.

18. Pereira CS, Possas CA, Viana CM, Rodrigues DP. Aeromonas spp. e Plesiomonas shigelloides isoladas a partir de mexilhões (Perna perna) in natura e précozidos no Rio de Janeiro, RJ. Ciênc. Tecnol. Aliment.2004; 24 (4).
19. Figueiras MJ, Soler L, Chacón MR, Guarro J, Martinez- Murcia AJ. Extended method for discrimination of Aeromonas spp.. by $16 \mathrm{~s}$ rDNA RFLP analysi. Int. J. Syst. Evol. Microbiol. 2000; 50: 2069-73.

20. Arora SK, Neely AN, Blair B, Lory S, Ramphal R. Role of motility and flagellin glycosylation in the pathogenesis of Pseudomonas aeruginosa burn wound infections. Infect Immun. 2005; 73 (7): 43958.

21. Wahli T, Burr SE, Pugovkin D, Mueller O, Frey J. Aeromonas sobria, a causative agent of disease in farmed perch, Perca fluviatilis L. J. Fish Dis. 2005; 28: $141-50$.

22. Kozinska A, Figueras MJ, Chacon MR, Soler L. Phenotypic characteristics and pathogenicity of Aeromonas genomo species isolated from common carp (Cyprinus carpio L.). J. Appl. Microbiol. 2002; 93 (6): 1034-41.

23. Castro-Escarpulli F, Figueras MJ, Aguilera-Arreola G, Soler L, Fernandez-Rendon E, Aparício GO, et al. Characterisation of Aeromonas spp. isolated from frozen fish intended for human consumption in México. Int. J. Food Microbiol. 3003; 84 (1): 41- 49.

24. Graf J. Diverse Restriction Fragment Length Polymorphism Patterns of the PCR-Amplified 16S rRNA Genes in Aeromonas veronii Strains and Possible Misidentification of Aeromonas Species. J. Clin. Microbiol. 1999; 37 (10): 3194-7.

25. Ormen O, Granum PE, Lassen J, Figueiras MJ. Lack of agreement between biochemical and genetic identification of Aeromonas spp. APMIS. 2005; 113: 203-7.

26. Huys G, Kampfer P, Albert MJ, Kuhn I, Denys R, Swings J. Aeromonas hydrophila subsp. Dhakensis subsp. nov., isolated from children with diarrhoea in Bangladesh, and extended description of Aeromonas hydrophila subsp. Hydrophila (Chester 1901) Stanier 1943 (Approved Lists 1980).Int. 1 J. System. Evol. Microbiol. 2002; 52: 705-12.

27. Miñana-Galbis D, Farfán MM, Fusté MC, Lorén JG. Aeromonas bivalvium sp. nov., isolated from bivalve mollusks. Int. J. Syst. Evol. Microbiol. 2007; 57: 582-7. 